\title{
STUDI EKSPERIMENTAL DAN SIMULASI TURBULENSI PENGARUH VARIASI PUTARAN TERHADAP KARAKTERISTIK KEBISINGAN PROTOTIPE PROPELLER RENDAH BISING
}

\author{
Afrizal Nurfi ${ }^{1}$, Ikhwansyah Isranuri ${ }^{2}$, M. Sabri ${ }^{3}$, Marragi M. ${ }^{4}$, Pramio G. Sembiring ${ }^{5}$ \\ 1,2,3,4,5 Departemen Teknik Mesin, Fakultas Teknik, Universitas Sumatera Utara \\ E-mail : afrizalnurfi276@yahoo.com
}

\begin{abstract}
ABSTRAK
Pesawat model adalah pesawat terbang tanpa awak yang dikendalikan dari jarak jauh oleh pilot atau mampu mengendalikan dirinya sendiri sesuai dengan program yang telah ditentukan. Pesawat tak berawak berfungsi untuk keperluan pengintaian atau untuk misi ke luar angkasa misalnya oleh militer atau badan luar angkasa disebut UAV (Unmanned Air Vehicle). Permasalahan kebisingan pada pesawat tanpa awak sedang menjadi konsentrasi penelitian yang terus meningkat dari tahun ke tahun. Salah satu syarat yang harus dipenuhi oleh pesawat tanpa awak yang bertujuan untuk melakukan pengintaian adalah rendahnya tingkat kebisingan dari pesawat tersebut. Sumber utama dari kebisingan pesawat yang digerakkan oleh propeller terletak pada propeller itu sendiri. Penelitian ini bertujuan untuk melakukan kajian eksperimental karakteristik dan menganalisa kebisingan serta energi turbulensi pada sebuah prototipe propeller rendah bising. Pengukuran dilakukan dengan variasi putaran $600 \mathrm{rpm}-1800 \mathrm{rpm}$ dengan metode bola (spherical method). Dari analisa kebisingan yang dihasilkan dari prototipe propeller nilai kebisingan terbesar terdapat pada arah aksial (Y+) di putaran $1800 \mathrm{rpm}$ jarak $1 \mathrm{~m}$ dengan nilai $90.2 \mathrm{~dB}$ dan nilai energi turbulensinya $22.438 \mathrm{~J} / \mathrm{Kg}$.
\end{abstract}

Kata kunci : Pesawat model, UAV, Propeller, Spherical method, Kebisingan, Turbulensi

\section{PENDAhULUAN}

\subsection{Latar Belakang}

Indonesia merupakan negara kepulauan yang luas seluruhnya $5.193 .250 \mathrm{~km}^{2}$, dan hampir dua pertiga wilayah Indonesia merupakan wilayah perairan dengan luas mencapai $3.287 .010 \mathrm{~km}^{2}$. Dengan wilayah laut yang luas tersebut, Indonesia memiliki potensi sumber daya kelautan (hayati dan non hayati) yang sangat bernilai tinggi untuk dapat dimanfaatkan secara optimal untuk kelangsungan hidup bangsa. Kondisi ini tentunya membutuhkan pengamanan sehingga sumber daya yang dimiliki Indonesia tidak berpindah ke negara lain.

Berdasarkan fakta tersebut, sangat perlu untuk mengembangkan sebuah pesawat udara tanpa awak(Unmanned Aerial Vehicle atau disingkat UAV) yang bertujuan sebagai sarana pendukung pemantauan keadaan wilayah Indonesia untuk mendapatkan data yang lebih detail, real time, cepat, dan murah. Pesawat udara tanpa awak (Unmanned Aerial Vehicle) merupakan sebuah wahana terbang yang dikendalikan dari jarak jauh untuk melakukan misi tertentu. Salah satu syarat yang harus dipenuhi oleh pesawat tanpa awak yang bertujuan untuk melakukan pengintaian adalah rendahnya tingkat kebisingan dari pesawat tersebut.

Namun seperti halnya mesin lainnya, permasalahan kebisingan merupakan hal yang tidak terelakkan. Sumber utama dari kebisingan pesawat yang digerakkan oleh propeller terletak pada sudut lengkung dan sudut twistnya [1].

\section{TINJAUAN PUSTAKA}

\subsection{Propeller}


Propeller merupakan sekelompok sayap berputar yang dibentuk bengkok, yang ditujukan agar menciptakan arah dari resultan gaya angkat yang menuju ke depan. Pada umumnya propeller terdiri dari dua atau lebih baling yang dihubungkan ke central hub yang merupakan bagian dimana baling - baling pesawat tersambung. Propeller berfungsi untuk mengubah gaya rotasi dari mesin menjadi gaya propulsif sebagai gaya dorong (Thrust) untuk pesawat [2].

\subsection{Bagian - Bagian Propeller}

Untuk menjelaskan teori propeller, perlu terlebih dahulu mengetahui bagian - bagian dari geometri propeller sebagai berikut :

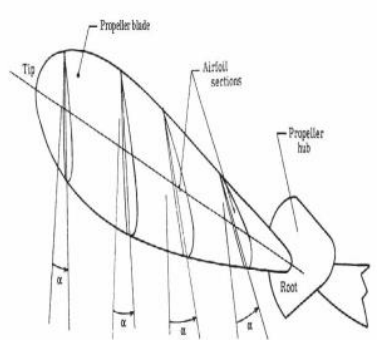

Gambar 2.1 Bagian - bagian propeller [2]

Berikut adalah bagian - bagian yang terdapat pada sebuah propeller:

1. Tip

Merupakan bagian terluar propeller dari Hub.

2. Root

Adalah bagian dari baling yang terdekat dengan hub.

3. Hub

Merupakan pusat propeller sebagai bagian dimana baling - baling melekat.

\subsection{Sound Pressure}

Sound presure merupakan fluktuasi dari tekanan udara. Ketika suatu sumber bunyi menghasilkan bunyi, maka buyi tersebut akan merambat melalui medium udara yang ada disekitarnya. Ketika terjadi perambatan, maka terjadi perubahan tekanan atmosfir beberapa saat. Sesuatu yang merupakan perubahan tekanan udara sebagai indikasi dari adanya permabatan bunyi inilah yang di sebut dengan sound pressure [3].

\subsection{Sound Power}

Sedangkan sound power merupakan sejumlah daya yang dapat di ukur dihasilkan oleh radiasi sumber bunyi yang menyebar disekitar udara. Secara matemetik, sound power dapat di rumuskan sebagai berikut:

$$
\mathrm{W}_{\mathrm{s}}=\left(4 \pi \mathrm{r}^{2}\right) I_{\max }(\text { watt })
$$

Untuk mempermudah penentuan nilai kebisingan, maka ada metode yang digunakan dengan menggunakan skala level atau tingkat kebisingan suara dalam satuan decibel (dB) yang dibagi menjadi dua kategori yakni sound pressure level dan sound power level.

\subsection{Sound Power level (SWL) \\ Sound power level dapat di rumuskan sebagai berikut :}


$\mathrm{L}_{\mathrm{w}}=10 \log \frac{W}{W_{\text {ref }}} \quad(\mathrm{dB})$

Dimana :

$\mathrm{W}=$ Sound power

$\mathrm{W}_{\text {reff }}=$ Sound power referensi dengan standar $10^{-12}$ watt

\subsection{Sound Pressure Level (SPL)}

Sedangkan sound pressure level dapat dirumuskan sebagai berikut :

$$
\begin{aligned}
\mathrm{SPL}=\mathrm{L}_{\mathrm{p}} & =10 \log \left[\frac{P^{2}}{P(\text { ref })^{2}}\right] \\
& =20 \log \frac{p}{p(\text { ref })}
\end{aligned}
$$

Dimana :

$\mathrm{P} \quad=$ Tekanan yang terjadi $\left(P_{r m s}\right)$ untuk aliran fluida

$\mathrm{P}(\mathrm{ref})=$ Tekanan pada air borne

$=2 \times 10^{-5} \mathrm{~N} / \mathrm{m}^{2}=20 \mu \mathrm{Pa}$

\subsection{Noise}

Noise adalah bunyi atau suara yang tidak dikehendaki dan dapat mengganggu kesehatandan kenyamanan lingkungan yang dinyatakan dalam satuan decibel ( $d B$ ) [4].

Sumber noise dapat dikelompokkan dalam tiga kategori:

1. Sumber noise intrinsik yang muncul dari fluktuasi acak di dalam suatu sistem fisik seperti thermal dan shot noise.

2. Sumber noise buatan manusia seperti motor, switch, elektronika digital.

3. Noise karena gangguan alamiah seperti petir dan bintik matahari.

Tabel 2.1 Contoh SPL Berdasarkan Sumbernya [5].

\begin{tabular}{lll}
\hline No & $\begin{array}{l}\text { Sound Sources(Noise) } \\
\text { Examples with Distance }\end{array}$ & SPL(dB) \\
\hline 1. & Jet aircraft, 50 m away & 140 \\
2 & Threshold of pain & 130 \\
3 & Threshold of discomfort & 120 \\
4 & Chainsaw, 1 m distance & 110 \\
5 & Disco, 1 m from speaker & 100 \\
6 & Diesel truck, 10 m away & 90 \\
7 & Kerbside of busy road, 5m & 80 \\
8 & Vacuum cleaner, distance $1 \mathrm{~m}$ & 70 \\
9 & Conversational speech, 1 m & 60 \\
10 & Average home & 50 \\
11 & Quite library & 40 \\
12 & Quite bedroom at night & 30 \\
13 & Background in TV studio & 20 \\
14 & Rustiling leaves in the distance & 10 \\
15 & Threshold of hearing & 0 \\
\hline
\end{tabular}

\subsection{Sinyal Noise}


Untuk suatu peristiwa pentransmisian data, sinyal yang diterima akan berisikan sinyal sinyal yang ditransmisikan, dimodifikasi oleh berbagai distorsi yang terjadi melalui sistem transmisi, ditambah sinyal - sinyal tambahan yang tidak diinginkan yang diselipkan di suatu tempat diantara transmisi dan penerimaan. Noise merupakan faktor utama yang membatasi performansi sistem komunikasi.

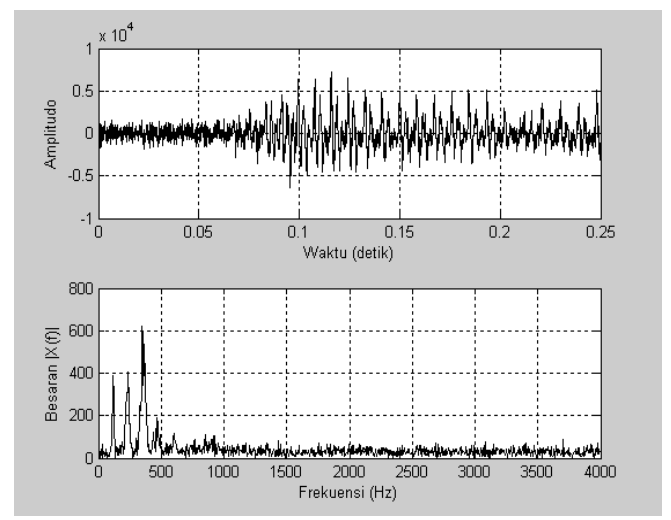

Gambar 2.1. Grafik sinyal noise [6]

\subsection{Noise Contour}

Sebuah kebisingan contour merupakan distribusi dari sumber kebisingan yang di gambarkan dalam bentuk garis yang bersambung dan tidak dapat bertemu atau memotong garis kontur lainnya dan tidak pula dapat bercabang menjadi garis kontur yang lain. Kontur kebisingan digunakan untuk menentukan distribusi sebaran bunyi sebagai bagian dari pengandalian kebisingan [6].

\section{METODOLOGI PENELITIAN}

\subsection{Tempat dan Waktu}

Penelitian ini dilaksanakan sejak tanggal 29 Juli 2014 pengesahan usulan oleh pengelola program studi sampai dinyatakan selesai yang direncanakan berlangsung selama \pm 4 bulan. Tempat pelaksanaan penelitian adalah di Research Center Noise/Vibration Control and Knowledge Based in Engineering, Program Magister Teknik Mesin, Fakultas Teknik, Universitas Sumatera Utara.

\subsection{Bahan Penelitian}

Bahan yang digunakan dalam melakukan penelitian ini adalah sebagai berikut yang terdapat pada tabel 3.1.

Tabel 3.1. Bahan Penelitian

\begin{tabular}{|c|c|c|c|}
\hline No & Nama & Spesifikasi & Jumlah \\
\hline 1. & Propeller & $\begin{array}{l}\text { Structure : Kandungan } 94 \% \mathrm{Al}- \\
6 \% \mathrm{Mg}\end{array}$ & \\
\hline & & $\begin{array}{l}\text { Tipe : CLARK Y } \\
\text { Number of blade : } 2\end{array}$ & 2 Unit \\
\hline 2. & Elektromotor & $\begin{array}{l}\text { LM - Motor, } 3 \text { Phase } 10 \mathrm{Hp}(7,5 \\
\mathrm{KM}, 2900 \mathrm{rpm}\end{array}$ & 1 Unit \\
\hline 3. & Inverter & LSIS AC 380 - $480 \mathrm{~V}$ & 1 Unit \\
\hline 4. & $\begin{array}{l}\text { Dudukan tabung } \\
\text { silinder }\end{array}$ & $\begin{array}{l}\emptyset 1000 \mathrm{~mm} \text {, Material plat Galvanis } \\
1,5 \mathrm{~mm}\end{array}$ & 1 Unit \\
\hline
\end{tabular}




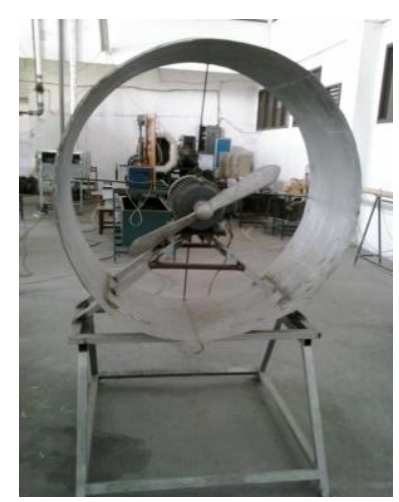

Gambar 3.1. Propeller

\subsection{Alat Penelitian}

Dalam proses penelitian ini banyak alat-alat teknik yang digunakan, dimana alat-alat yang digunakan memiliki fungsi dan kegunaan masing - masing dalam proses penelitian ini. Adapun alat - alat tersebut antara lain :

\section{Sound Level Meter}

Sound Level Meter merupakan alat yang digunakan untuk mengukur seberapa besar suara bising mempengaruhi pekerja dalam melaksanakan tugasnya. Fungsi alat ini untuk mengukur intensitas kebisingan antara $30-130 \mathrm{~dB}$ dan dari frekuensi $20-20.000 \mathrm{~Hz}$.

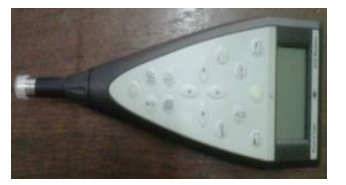

Gambar 3.2. Sound level meter

\section{Tripod}

Tripod adalah alat stan untuk membantu agar badan kamera bisa berdiri dengan tegak dan tegar. Hal ini dimaksudkan untuk mengurangi kelelahan fotografer dalam mengambil gambar dan mengurangi noise yang ditimbulkan oleh guncangan tangan fotografer. Tripod yang digunakan dalam penelitian ini bermerek Ouyama.

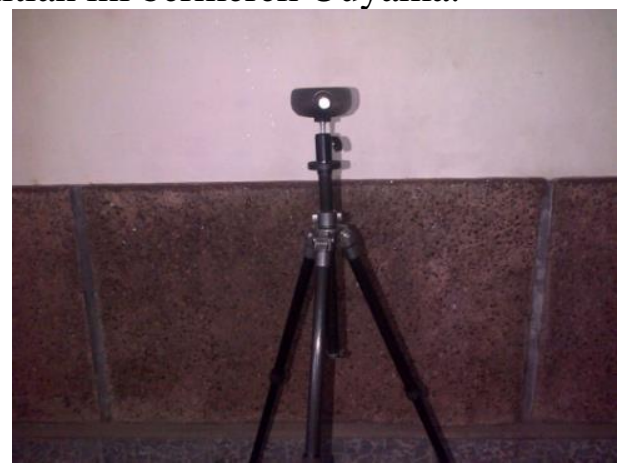

Gambar 3.3. Tripod 


\subsection{Pengujian Kebisingan Prototipe Propeller}

Secara eksperimental pengujian dan pengambilan data dilakukan untuk memperoleh karakteristik kebisingan yang ditransmisikan dari motor ke propeller. Pengujian dilakukan dengan memutar propeller dengan putaran 600 - $1800 \mathrm{rpm}$. Pada saat propeller berputar akan dilihat kebisingan yang dihasilkan oleh prototipe propeller dengan menggunakan alat uji kebisingan .

Setelah didapatkan hasil pengujian kebisingan prototipe propeller berupa angka digital yang tertera di sound level meter, kemudian data tersebut diolah dengan menggunakan microsoft excel sehingga didapatkan nilai sound level meter dan sound pressure meter.

\subsection{Variabel Yang Diamati}

Sesuai dengan maksud eksperimen, variabel ini menjadi fokus perhatian yang perlu dikondisikan untuk pengolahan data guna mendapatkan hasil yang mendekatin sempurna. Adapun variabel yang diamati dalam studi eksperimental ini adalah sebagai berikut :

1. Jarak sound level meter Bruel \& Kjaer type 2238 fulfils ke propeller.

2. Frekuensi dari inverter.

3. Noise pada propeller dengan arah horizontal, vertical, aksial.

4. Turbulensi

\section{ANALISA DATA}

\subsection{Data hasil pengukuran}

Pengukuran dilakukan di Laboratorium Noise and Vibration Research Center dengan kebisingan awal $37.8 \mathrm{~dB}$. Pengukuran diambil dari arah $\mathrm{Y}+, \mathrm{Y}-, \mathrm{X}+, \mathrm{X}-, \mathrm{Z}+, \mathrm{Z}-$. Arah pengukuran dapat dilihat pada gambar 4.1 sebagai berikut :

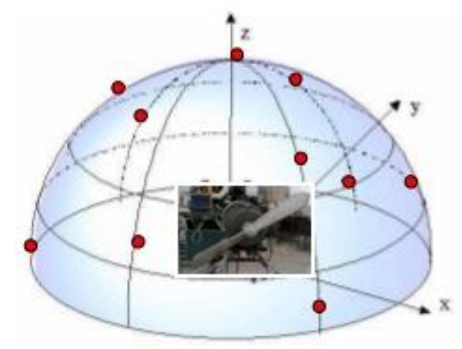

Gambar 4.1. Arah pengukuran propeller

Berikut ini adalah grafik kebisingan vs putaran yang terjadi pada propeller.

1. Grafik Kebisingan Vs Putaran Pada Jarak $1 \mathrm{~m}$ 


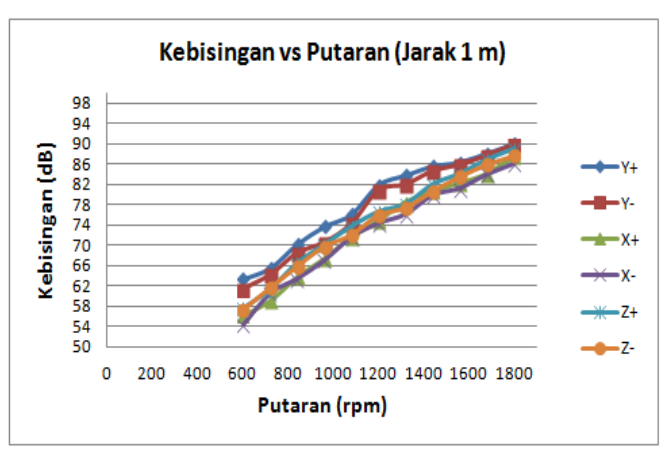

Gambar 4.2. Grafik kebisingan vs putaran pada jarak 1 meter

Berdasarkan grafik diatas dapat kita lihat bahwa putaran dan kebisingan berbanding lurus yaitu semakin tinggi putaran semakin tinggi kebisingan yang dihasilkan.

2. Grafik Kebisingan Vs putaran Pada Jarak $3 \mathrm{~m}$

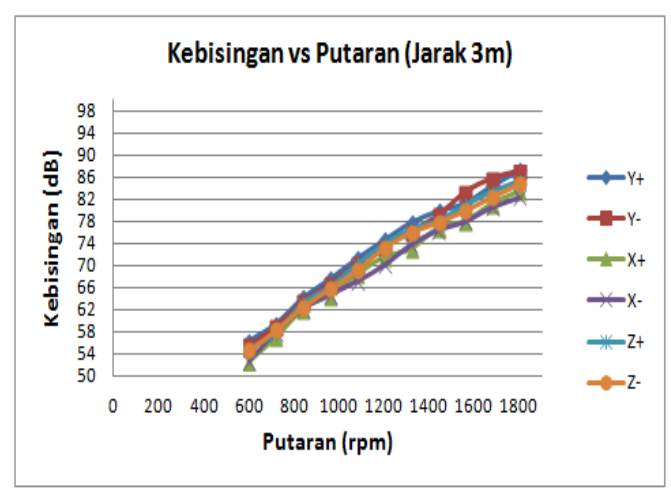

Gambar 4.3. Grafik kebisingan vs putaran pada jarak 3 meter

Grafik diatas juga menunjukkan hal yang sama dengan grafik sebelumnya, bahwasanya semakin tinggi putaran mesin semakin tinggi pula noise yang di hasilkan.

1. Grafik Kebisingan Vs Putaran Pada Jarak $5 \mathrm{~m}$

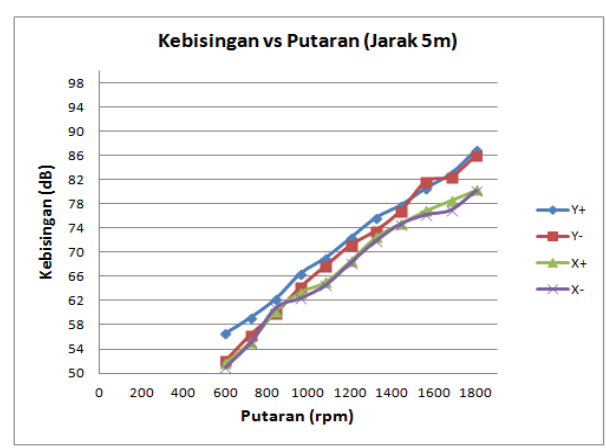

Gambar 4.4. Grafik kebisingan vs putaran pada jarak 5 meter

Pada jarak 5 meter kebisingan turun secara drastis, ini disebabkan karena jarak propeller dengan sound level meter yang cukup jauh. Namun demikian tetap putaran dan kebisingan berbanding lurus. 


\subsection{Noise Contour}

Dibawah ini merupakan gambar noise contour yang dihasilkan pada arah $\mathrm{Y}+, \mathrm{Y}-, \mathrm{X}+$, $\mathrm{X}-, \mathrm{Z}+, \mathrm{Z}$ - dengan variasi putaran $600 \mathrm{rpm}, 1200 \mathrm{rpm}$, dan $1800 \mathrm{rpm}$.

1. Jarak 1 meter

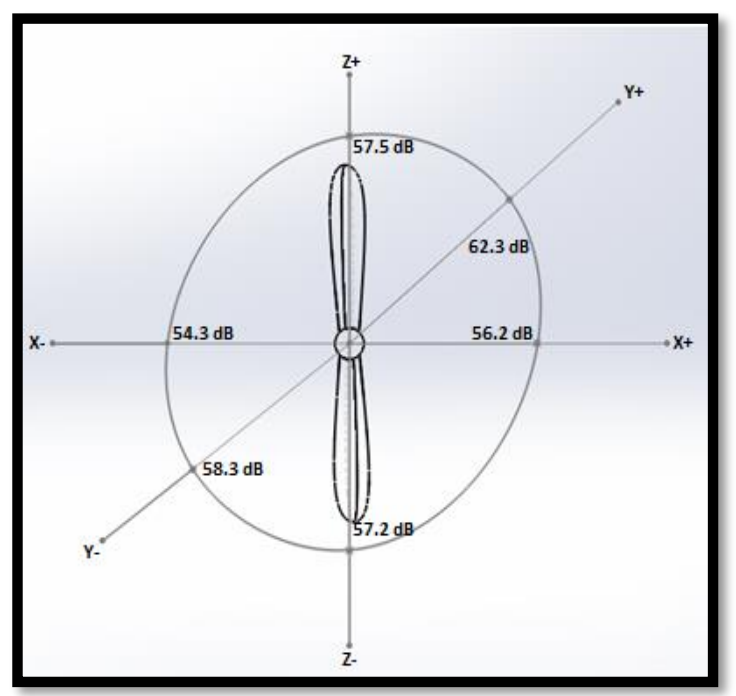

Gambar 4.5. Noise Contour pada propeller (jarak 1m, 600 rpm)

Gambar 4.5 memperlihatkan tingkat kebisingan tertinggi berada pada sumbu $\mathrm{Y}+(62.3$ dB) dan kebisingan paling rendah berada pada sumbu $X+(54.3 \mathrm{~dB})$ dengan $600 \mathrm{rpm}$. Bentuk noise contour diperlihatkan seperti gambar diatas.

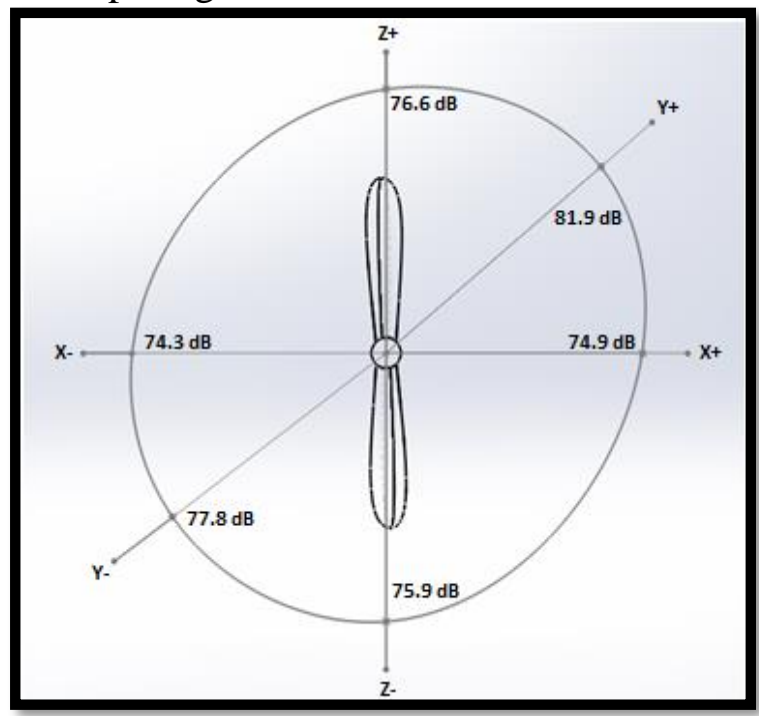

Gambar 4.6. Noise Contour pada propeller (jarak 1m, 1200 rpm)

Gambar 4.6 memperlihatkan tingkat kebisingan tertinggi berada pada sumbu $\mathrm{Y}+$ (81.9 dB) dan kebisingan paling rendah berada pada sumbu X- (74.3 dB) dengan kecepatan $1200 \mathrm{rpm}$. Bentuk noise contour diperlihatkan seperti gambar diatas. 


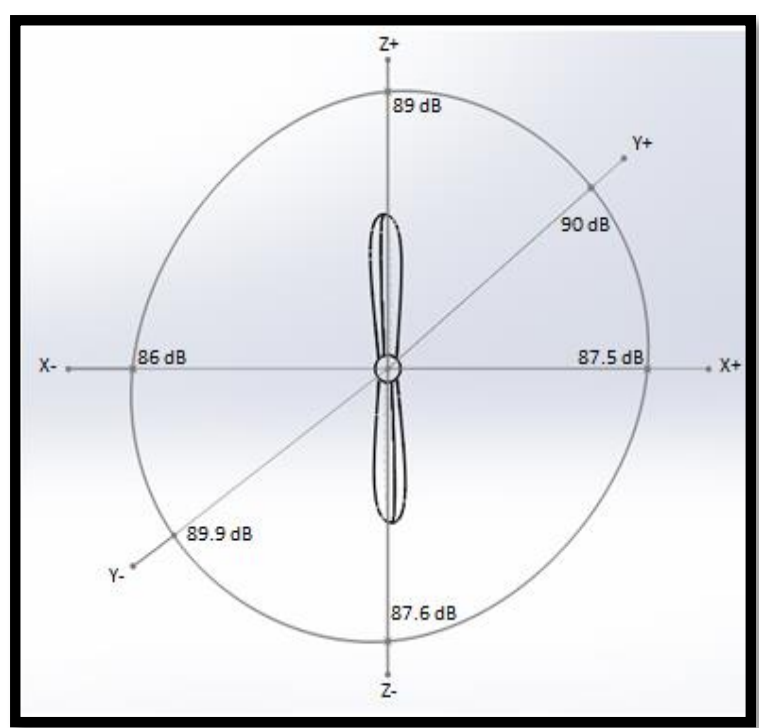

Gambar 4.7. Noise Contour pada propeller (jarak 1m, 1800 rpm)

Gambar 4.7 memperlihatkan tingkat kebisingan tertinggi berada pada sumbu $\mathrm{Y}+(93.2$ dB) dan kebisingan paling rendah berada pada sumbu X- (86 dB) dengan kecepatan 1800 rpm. Bentuk noise contour diperlihatkan seperti gambar diatas.

\section{Jarak 3 meter}

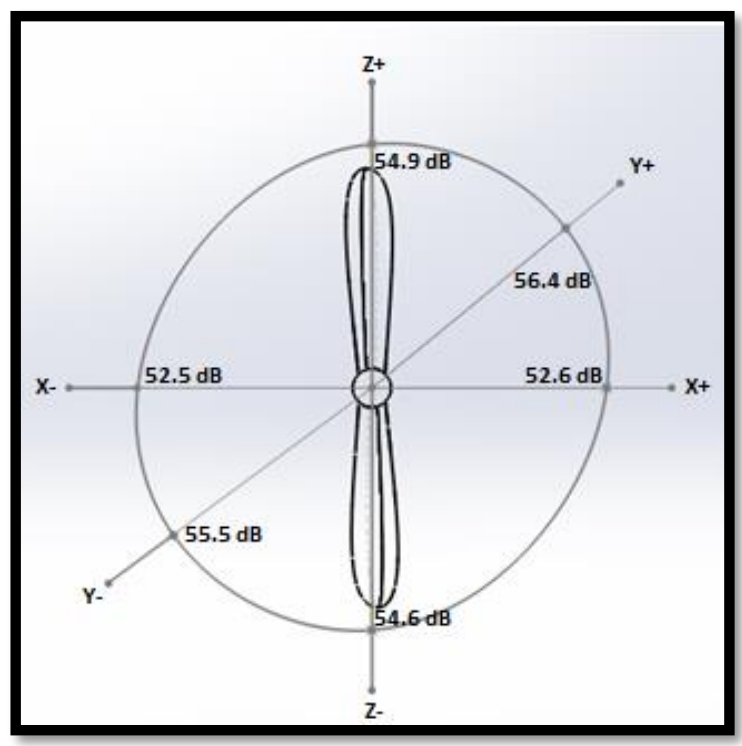

Gambar 4.8. Noise Contour pada propeller (jarak 3 m, 600 rpm)

Gambar 4.8 memperlihatkan tingkat kebisingan tertinggi berada pada sumbu $\mathrm{Y}+(56.4$ dB) dan kebisingan paling rendah berada pada sumbu X- $(52.5 \mathrm{~dB})$ dengan kecepatan 600 rpm. Bentuk noise contour diperlihatkan seperti gambar diatas. 


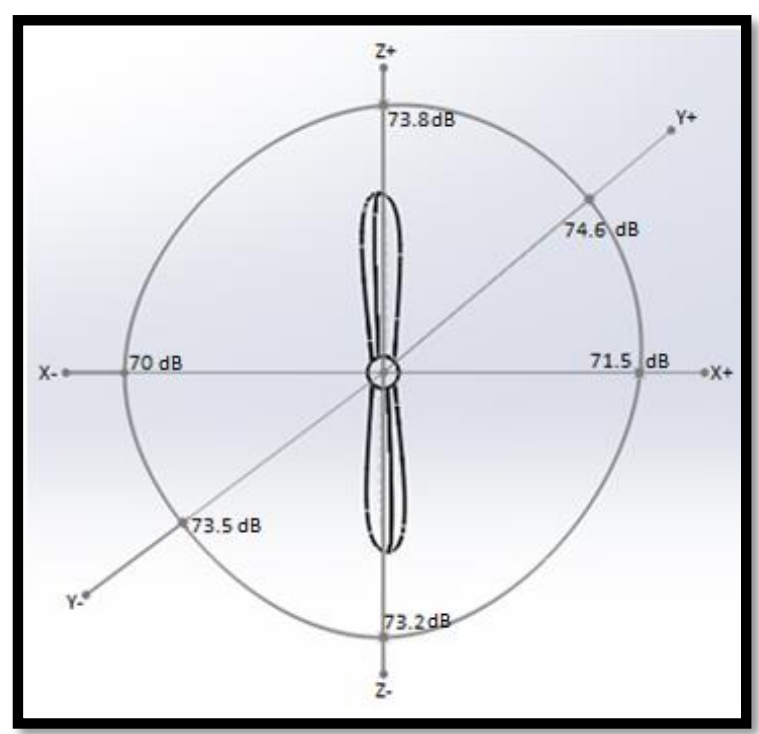

Gambar 4.9. Noise Contour pada propeller (jarak 3 m, 1200 rpm)

Gambar 4.9 memperlihatkan tingkat kebisingan tertinggi berada pada sumbu $\mathrm{Y}+(74.6$ dB) dan kebisingan paling rendah berada pada sumbu X- (70 dB) dengan kecepatan 1200 rpm. Bentuk noise contour diperlihatkan seperti gambar diatas.

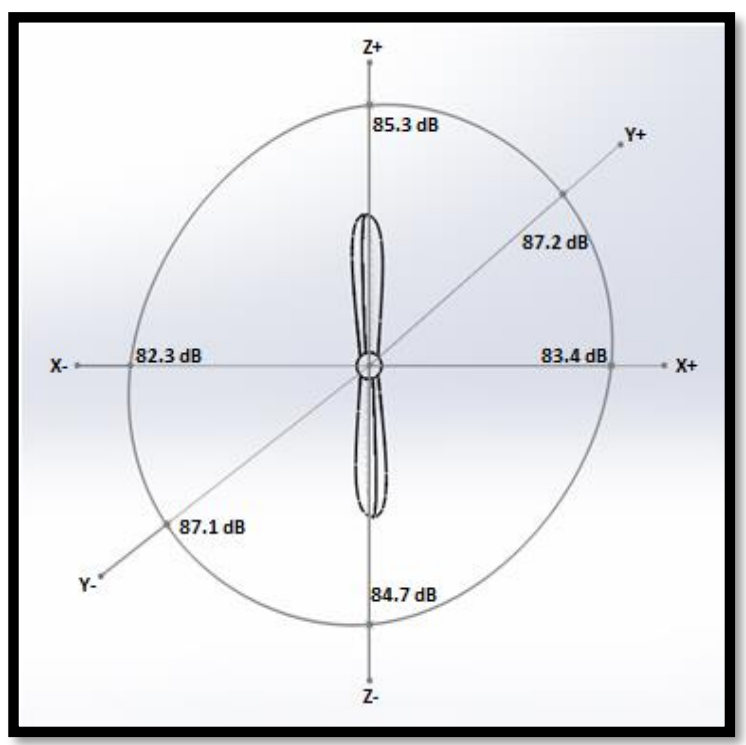

Gambar 4.10. Noise Contour pada propeller (jarak 3 m, 1800 rpm)

Gambar 4.10 memperlihatkan tingkat kebisingan tertinggi berada pada sumbu $\mathrm{Y}+(87.2$ dB) dan kebisingan paling rendah berada pada sumbu X- (82.3 dB) dengan kecepatan 1800 rpm. Bentuk noise contour diperlihatkan seperti gambar diatas.

\subsection{Analisa Kebisingan}

\section{Sound Power Level}


$\mathrm{L}_{\mathrm{w}}=10 \log \frac{W}{W_{\text {ref }}} \quad(\mathrm{dB})$

Diketahui :

$$
\begin{aligned}
\mathrm{W} & =10 \mathrm{Hp} \\
& =10 \times 745,7 \text { Watt } \\
& =7457 \text { Watt } \\
\mathrm{W}_{\text {reff }} & =10^{-12}
\end{aligned}
$$

Sehingga :

$$
\begin{aligned}
\mathrm{L}_{\mathrm{w}} & =10 \log \left(7457 / 10^{-12}\right) \\
& =158,7256 \mathrm{~dB}
\end{aligned}
$$

2. Sound Pressure Level (SPL)

$$
\begin{gathered}
S P L=L p=20 \log \frac{p}{p_{\text {ref }}} \\
p=p_{\text {ref }} \times 10^{\frac{L p}{20}}
\end{gathered}
$$

Diketahui :

\begin{tabular}{|c|c|c|c|c|c|c|c|}
\hline \multirow[t]{2}{*}{ No } & \multirow[t]{2}{*}{$\mathrm{N}(\mathrm{rpm})$} & \multicolumn{3}{|c|}{$\mathrm{Y}+$} & \multicolumn{3}{|c|}{$Y-$} \\
\hline & & $1 \mathrm{~m}$ & $3 \mathrm{~m}$ & $5 \mathrm{~m}$ & $1 \mathrm{~m}$ & $3 \mathrm{~m}$ & $5 \mathrm{~m}$ \\
\hline 1 & 600 & 0.0261 & 0.0132 & 0.0135 & 0.0164 & 0.0119 & 0.0081 \\
\hline 2 & 720 & 0.0377 & 0.0189 & 0.0182 & 0.0255 & 0.0178 & 0.0132 \\
\hline 3 & 840 & 0.0647 & 0.0324 & 0.0261 & 0.0526 & 0.0303 & 0.02 \\
\hline 4 & 960 & 0.0968 & 0.048 & 0.0423 & 0.067 & 0.0433 & 0.0328 \\
\hline 5 & 1080 & 0.1607 & 0.0735 & 0.057 & 0.1026 & 0.0662 & 0.0491 \\
\hline 6 & 1200 & 0.2489 & 0.1074 & 0.0834 & 0.1552 & 0.0946 & 0.0726 \\
\hline 7 & 1320 & 0.3476 & 0.1552 & 0.1219 & 0.2 & 0.1291 & 0.0957 \\
\hline 8 & 1440 & 0.4276 & 0.1977 & 0.1552 & 0.3027 & 0.1803 & 0.14 \\
\hline 9 & 1560 & 0.4688 & 0.2323 & 0.2143 & 0.4426 & 0.2924 & 0.2432 \\
\hline 10 & 1680 & 0.6325 & 0.3358 & 0.2825 & 0.6855 & 0.39 & 0.2667 \\
\hline 11 & 1800 & 0.9142 & 0.4582 & 0.4426 & 0.8148 & 0.4529 & 0.3991 \\
\hline
\end{tabular}

$\mathrm{Lp} \quad=62.3 \mathrm{~dB}$ (kebisingan yang dihasilkan propeller)

$\mathrm{p}_{\mathrm{ref}} \quad=2 \times 10^{-5} \mathrm{~N} / \mathrm{m}^{2}$

Sehingga :

$$
62,3=20 \log \frac{p}{2 \times 10^{-5}} \quad p=2 \times 10^{-5} \times 10^{\left(\frac{62.3}{20}\right)}=0.0261
$$

Dengan menggunakan rumus yang sama seperti diatas dapat kita cari tekanan yang dihasilkan pada propeller dan ditabelkan pada tabel 4.4 sebagai berikut:

Tabel 4.4 Tekanan pada prototipe propeller rendah bising. 


\begin{tabular}{cccccccccc}
\hline & $\mathrm{X}+$ & & \multicolumn{3}{c}{$\mathrm{X}-$} & & $\mathrm{Z}+$ & & $\mathrm{Z}-$ \\
$1 \mathrm{~m}$ & $3 \mathrm{~m}$ & $5 \mathrm{~m}$ & $1 \mathrm{~m}$ & $3 \mathrm{~m}$ & $5 \mathrm{~m}$ & $1 \mathrm{~m}$ & $3 \mathrm{~m}$ & $1 \mathrm{~m}$ & $3 \mathrm{~m}$ \\
\hline 0.0129 & 0.0085 & 0.0077 & 0.0104 & 0.0084 & 0.0071 & 0.015 & 0.0111 & 0.0145 & 0.0107 \\
0.018 & 0.0142 & 0.0115 & 0.0212 & 0.0157 & 0.0114 & 0.0232 & 0.0159 & 0.0238 & 0.0164 \\
0.031 & 0.0255 & 0.0207 & 0.0296 & 0.0258 & 0.0219 & 0.0423 & 0.0292 & 0.039 & 0.0267 \\
0.0469 & 0.034 & 0.0296 & 0.0448 & 0.0344 & 0.0264 & 0.064 & 0.0408 & 0.0611 & 0.039 \\
0.076 & 0.0526 & 0.036 & 0.076 & 0.0453 & 0.034 & 0.0968 & 0.0655 & 0.0796 & 0.057 \\
0.1112 & 0.0752 & 0.0538 & 0.1038 & 0.0632 & 0.052 & 0.1352 & 0.098 & 0.1247 & 0.0914 \\
0.1683 & 0.0893 & 0.0843 & 0.1277 & 0.098 & 0.0787 & 0.1607 & 0.1352 & 0.1483 & 0.1262 \\
0.2168 & 0.1384 & 0.1099 & 0.1954 & 0.1321 & 0.1087 & 0.2518 & 0.1607 & 0.2143 & 0.1552 \\
0.2576 & 0.1589 & 0.14 & 0.2296 & 0.1589 & 0.1291 & 0.3206 & 0.2244 & 0.2992 & 0.1977 \\
0.3206 & 0.2296 & 0.1702 & 0.3134 & 0.2143 & 0.1416 & 0.4426 & 0.2958 & 0.3945 & 0.2637 \\
0.4743 & 0.2958 & 0.207 & 0.3991 & 0.2606 & 0.2047 & 0.5637 & 0.3682 & 0.4798 & 0.3436 \\
\hline
\end{tabular}

\subsection{Analisa Turbulensi Propeller}

Analisa turbulensi propeller menggunakan software solid work 2013 dengan variasi putaran 600, 1200, $1800 \mathrm{rpm}$ dan jarak 1 meter. Adapun hasil gambar turbulensinya sebagai berikut :

1. Simulasi turbulensi propeller putaran $600 \mathrm{rpm}$

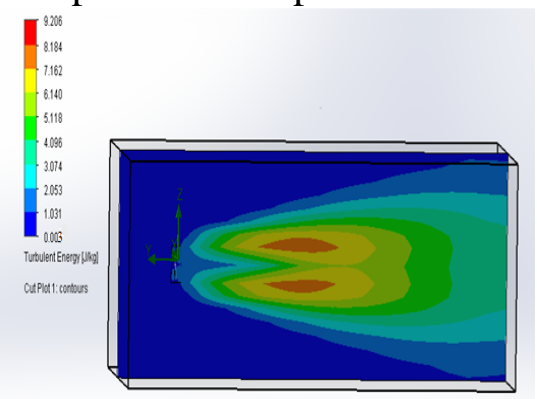

Gambar 4.11. Kontur energi turbulensi pada propeller (jarak $1 \mathrm{~m}, 600 \mathrm{rpm}$ )

Gambar 4.11 diatas memperlihatkan kontur turbulensi, terlihat bahwa turbulensi dari propeller dengan karakteristik yang terbelah dan mencapai nilai maksimum sekitar 8.095 $\mathrm{J} / \mathrm{Kg}$. Turbulensi pada propeller menghasilkan intensitas bunyi sekitar $70.7543 \mathrm{~dB}$.

2. Simulasi turbulensi propeller putaran $1200 \mathrm{rpm}$

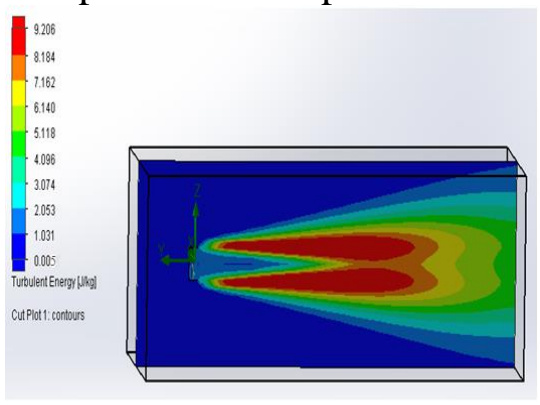

Gambar 4.12. Kontur energi turbulensi pada propeller (jarak 1 m, 1200 rpm)

Gambar 4.12 diatas memperlihatkan kontur turbulensi, terlihat bahwa turbulensi dari propeller dengan karakteristik yang terbelah dan mencapai nilai maksimum sekitar 14.341 $\mathrm{J} / \mathrm{Kg}$. Turbulensi pada propeller menghasilkan intensitas bunyi sekitar $87.74404 \mathrm{~dB}$. 
3. Simulasi turbulensi propeller putaran $1800 \mathrm{rpm}$

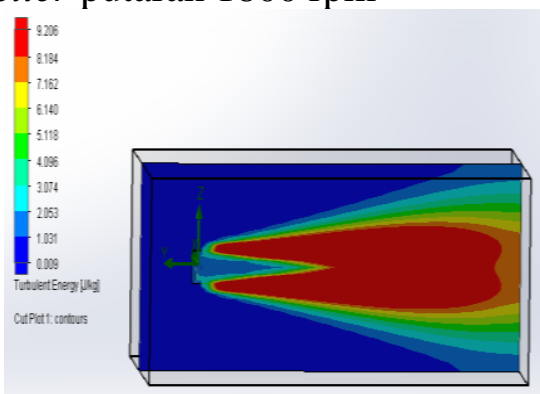

Gambar 4.13. Kontur energi turbulensi pada propeller (jarak 1 m, 1800 rpm)

Gambar 4.13 diatas memperlihatkan kontur turbulensi, terlihat bahwa turbulensi dari propeller dengan karakteristik yang terbelah dan mencapai nilai maksimum sekitar 22.438 $\mathrm{J} / \mathrm{Kg}$. Turbulensi pada propeller menghasilkan intensitas bunyi sekitar $90.29676 \mathrm{~dB}$.

\subsection{Perbandingan Hasil Kebisingan Eksperimental}

Dibawah ini merupakan perbandingan data hasil dari eksperimental dan simulasi antara lain :

Tabel 4.5 Data Hasil Eksperimental dan Simulasi

\begin{tabular}{|c|c|l|c|}
\hline \multirow{2}{*}{ No } & \multirow{N}{N}{} & $\begin{array}{c}\text { Data } \\
\text { Kebisingan } \\
(\mathrm{rpm})\end{array}$ & $\begin{array}{c}\text { Data } \\
\text { Simulasi } \\
\text { Eksperimental }\end{array}$ \\
\cline { 3 - 4 } & & 1 meter & 1 meter \\
\hline 1. & 600 & $63.3 \mathrm{~dB}$ & $70.7 \mathrm{~dB}$ \\
\hline 2. & 1200 & $81.9 \mathrm{~dB}$ & $87.7 \mathrm{~dB}$ \\
\hline 3. & 1800 & $90 \mathrm{~dB}$ & $90.2 \mathrm{~dB}$ \\
\hline
\end{tabular}

Perbandingan data hasil eksperimental dengan simulasi

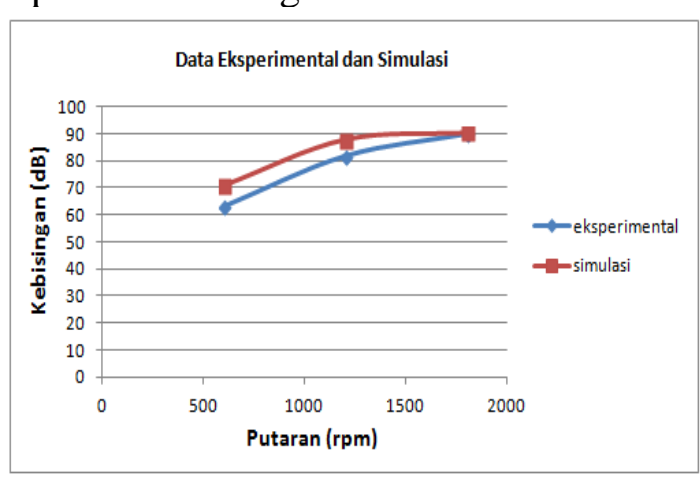

Gambar 4.14. Grafik perbandingan eksperimental dan simulasi

Gambar 4.14 memperlihatkan bahwa garis untuk data eksperimental dan simulasi jaraknya tidak begitu jauh. Bahkan garis pada putaran $1800 \mathrm{rpm}$ terlihat berimpit. Ini menunjukan hasil 
eksperimental dan simulasi menunjukan hasil yang sama. Semakin tinggi putaran yang dihasilkan maka semakin besar pula kebisingan yang dihasilkan.

\section{KESIMPULAN DAN SARAN}

\subsection{Kesimpulan}

Berdasarkan penelitian dan analisa yang telah dilakukan dan dilaporkan pada bab-bab sebelumnya, maka kesimpulan dari hasil penelitian ini yaitu:

1. Dari hasil pengujian eksperimental kebisingan pada propeller maka dapat disimpulkan semakin tinggi putaran mesin semakin tinggi pula nilai kebisingan yang di hasilkan.

2. Dari hasil pengukuran dan perhitungan dengan menggunakan rumus didapatkan nilai maximum sound pressure level pada arah (Y+) diputaran $1800 \mathrm{rpm}$ jarak 1 meter dengan nilai $90 \mathrm{~dB}$, tekanannya $0.6325 \mathrm{~Pa}$ dan nilai sound power level $158,7256 \mathrm{~dB}$.

3. Dari hasil simulasi didapatkan nilai energi turbulensi terbesar pada propeller diputaran $1800 \mathrm{rpm}$ dengan nilai min $0.008 \mathrm{~J} / \mathrm{Kg}, \max 22.438 \mathrm{~J} / \mathrm{Kg}$ dan intensitas bunyi 90.29676 dB.

\subsection{Saran}

1. Untuk penelitian selanjutnya, sebaiknya dilakukan pengujian aerodinamis pada tunnel tertutup sehingga didapatkan hasil aerodinamika propeller yang lebih baik. Hal ini bermanfaat untuk mendapatkan aliran fluida udara yang lebih akurat dan spesifik.

2. Penelitian terhadap propeller rendah bising ini kiranya dapat menjadi acuan dalam penelitian - penelitian yang sehubungan dengan konsep Low Noise Design selanjutnya.

3. Untuk penelitian selanjutnya, sebaiknya menggunakan paduan material propeller yang berbeda untuk memperoleh redaman kebisingan yang lebih tinggi.

\section{DAFTAR PUSTAKA}

[1]Ardhianto, Kurniawan. 2011. Desain dan Analisa Propeller pada Unmanned Aerial Vehicle (UAV). AAu Journal of Defense Science and Technology.

[2]Bant, RalphD., 1985, Aircraft Powerplants, Fifth Edition, United States of America : McGraw-Hill Book Co.

[3]Barron,Randall F. 2001. Industrial Noise Control and Acoustics. New-York : Marcel Dekker, Inc.

[4]Graham, J.B. (1991) in Harris, C.M. Handbook of acoustical measurements and noise control.

[5]Http://www.TableOfSoundPressureLevels.htm

[6]Harris, Cyril M.1957. Handbook of Noise Control. 